\title{
MARKETING COMMUNICATION IN THE INTERNET
}

\author{
Duhalm Simona, Assistant \\ UNIVERSITY OF BACAU
}

\section{Abstract:}

Currently, communication becomes more complex, faster and more dynamic every day. In this context, communication switches channels on traditional media to online applications. Thus, the electronic communication threatens, if not take the physical communication. We live in the era of information and the information they seek more ways than quick, cheap and accessible spread. Among the most common methods of electronic communication including website, electronic newsletter, blog and email custom. Online marketing has its roots in traditional marketing, but branch out and in a very obvious due to a unique features: interactivity. On the Internet, communication takes place in two directions and not just one, as in traditional marketing. At the same time, sellers and buyers can complete transactions from their homes or offices, at any time of day or night. Online marketing offers the advantage of presenting the interactive promotional materials that can meet the expectations of each type of buyer. Instead of creating a single message, as happens in the promotion of mass, marketing online allows the creation of "interactive brochure" that allow potential customers to choose the information that they want to see and when they want to see. Changing consumer behavior have had thoughts of marketing people who understand that the Internet is a very effective tool to attract, retain and loyalty the customer.

On the Internet, companies can create individualized sales presentations, tailored to each buyer. Online marketing allows companies to target their customers in a way that traditional media marketing can not. Online advertising is closer to selling personal than anything else. Each customer is seen as a single person with its own needs, lifestyle, preferences and purchasing patterns. One of the main objectives in pursuit of marketing on the Internet should be developing a comprehensive database that contains detailed information on existing customers and potential.

The development of information technologies allow a wide range of facilities for marketers such as a precise targeting both geographical and in terms of age and visitor preferences and consumer Web services. Another advantage is interactivity that provides Internet transforming the advertising into a dialogue (unlike the classic advertising, where it is rather a monologue). In addition, there is a very large variety of forms of advertising, from banner advertising, which can be images, text, animations, sound, image, video spots, etc. These are all interactive.
Consumers on the Internet differs from the way in addressing the procurement and respond to marketing. People who use the Internet gives greater importance to information and tend to respond negative to messages aimed only sell products and services. While traditional marketing deals with a somewhat passive audience, online marketing aimed at people who select effective Web sites on which they will visit with and banners that will click. Thus, online marketing, consumer control a large part of the interaction.

\section{Advantages and disadvantages of using the Internet as a medium of marketing communication Advantages of Internet are: \\ - targeting very good user segments} concerned, now technologies enabling that identify geographic location of the consumer online advertising and targeting a more complex matter of what your visitors, their age, income information, the budget earmarked for a specific category of products (some web pages that can be used as media), etc.;

- results that are measurable throughout the program and create a stage 
with a very low error with low cost compared to those of classical marketing research;

- rapid visibility and throughout the campaign, which gives a great addition to classical advertising media such as radio or $\mathrm{TV}$, where advertising spots are run at certain times and for a certain duration. Internet advertising is constantly circulated by a virtually unlimited number of visitors of the site which runs;

- sustainability over time (the articles are usually published in electronic archives) and low cost of maintenance of its existence;

- freedom of creativity, leading to innovative concepts (because of technology), appearing different forms, formats, concepts, techniques to promote products or services of a company;

- multiple channels show, many "tools" at hand;

- increased interactivity, obtaining rapid feedback, often even instant;

- awareness quickly;

- low costs.

But there are disadvantages such as:

- segments are concerned, however, limited in number, still can not speak of a "touch" the mass of the population, although growth rates audience are amazing of explosion due to technological development in recent years;

- although there are many results and measurable, times are few people to monitor and act in real time on this campaign because the actions and reactions are different from those of the classic marketing;

- lack of a specific method of programming can make the website information will not be found;

- lack of qualified personnel in industry, as a result of that is a relatively new field.

Internet environment is characterized by continuous growth in the number of users and the number of registered domains, improving the quality of content, information and services sites, increasing the amount and degree of sophistication of online advertising with an increased interest of advertisers to the Internet . Developing access to the Internet via cable and mobile phone services with the emergence of additional value added to the main ISP links (online services to protect the mail boxes, Customer Center, VoIP,)crystallisation of a group of major players, with entrepreneurial activities online, which develops networking sites to attract advertising or to provide applications and online services such as recruitment, virtual markets, etc., drafting and adopting legislation on the ITC also led to increasing the number of users.

Marketing on the Internet are very high chances to succeed if they offer free information of value, because customers who are searched on the Internet for information and leave convinced of concrete facts and logic. Companies that until now had to condense the advertising messages can enjoy a relatively unlimited space, the Internet allowing them to place a large quantity of multimedia information, consisting of text, pictures, graphics and sounds. Online marketing and provide the advantage that the metering accesses each page, to find out what potential customers are interested.

In marketing communication via the Internet site is an important strategic tool, as its characteristics: individualization and interactivity, is not only an event on the Internet, but also a channel for sale, a promotion and publicity tool, a tool for research, technology necessary to support a development strategy in the virtual market long-term.

A website is composed of websites, databases and other applications developed in PHP, ASP, Flash, etc.. Such applications include: registration forms, banners, logos. The core a web site is web page and a web page consists of text and image. The image can be static or dynamic. Dynamic image files can contain video and sound files.

The site can sell and bring the consumer closer to the decision to purchase, through the communication of information, customer support, promote technology, is interactive, giving opinions and satisfaction / insatisfaction customers.

The success of a site is determined by its quality, easy access to information and quality photos. Among the criteria that characterize the quality of the website include: 
- airworthiness (authentication ease, function menu, position within the site);

- the design (home page, layot, methods to capture the attention of the visitor);

- content information (information structure, the help, contact page);

- custom criteria (combining with airworthiness safety, ease of access demo, offered help in case of loss / theft of data authentication).

Being considered the most important promotional tool online can have a significant influence if it is continually updated and is promoted by registration in search engines and different databases.

Marketing on the Internet, small companies can compete for between equals with big companies. Small companies that develop and publish a Web site may seem good as professional and reliable companies such as large multinationals.

Blogs gaining ever more users and readers. A blog is a frequently updated journal published on the Internet for the general public, built on a platform of CMS (Content Management System). It is distinguished from other pages by the fact that the data are displayed in reverse order of their introduction.

Blogs provide information, comments, opinions about a favorite topic (eg political, advertising, local news, personal information), and content can be in text, audio, video. Modern blog evolved from online journals, which were started only updated components of the usual sites. With the development of programs that facilitate the introduction and display items in reverse chronological order, the process became accessible to a wider audience.

Blogs can be made at corporate level. A corporate blog is a blog published and used by an organization with the aim of reaching some targets / parameters, which are either effective or promotion.

Although in terms of personal blogs quickly expanding market, the corporate level we can not yet speak of a uniform coverage of the market. A little exercise in imagination: when a person calls the call service, prefer to speak with a robot or an employee? The same is true for customers of a company when it opens website would appreciate it if you see something other than a simple catalog presentation.

Banner is a tool used mostly in communication on the Internet. It must look attractive, to be in harmony with the site where it is placed.

To build a lasting relationship with the customer, must win the trust and to convey sincerity, and one of the most important ways to build trust is to promptly answer emails. This notify customers that are important for the company.

The company could encourage current and potential customers to send questions, suggestions and even complaints via email. Representatives are responsible for serving customers can respond quickly to such messages. The company can conceive, also lists the Internet-based with electronic addresses of current and prospective customers. These lists provide an excellent opportunity to present the company and its offerings to new customers and build relationships with current customers. Thus, market operators online can send to customers newsletters and offers related to certain products depending on the history of customer purchases made.

Communication via e-mail offers managers marketing communication and numerous priceless benefits from the rapid dissemination of the message to a large mass of receivers and to the minimum cost involved in this process, but use of the Internet in a chaotic and lacks efficiency can bring losses that can hardly recover.

Companies must be careful not to cause dissatisfaction among Internet users, due to multiple data. Must take into account that can irritate consumers when they sent unsolicited emails.

A key element that must be taken in online communication is that much time. Thus, for a more efficient use of time, not only that the information is easily and quickly accessible, but it becomes more succinct and to the point. Besides marketers are turning to new channels of communication is necessary to change the approach, using the expression 
language and brief informal these specific environments.

It is now increasingly hard to "aim" consumers through traditional methods, particularly the young. Therefore, the budgets allocated to Internet marketing in Western Europe will grow annually by $15 \%$ by 2012 . Europeans of the most developed browsing the Internet on average 14.3 hours per week, while the time spent watching TV is 11.3 hours. Meanwhile, 36\% of "internauți" mentions that watches television less because it allocates more time browsing the Internet.

Changes in terms of consumer behavior have had thoughts of marketing people who understand that the Internet is a very effective tool for attracting, retaining and loialisyng customers. Therefore, companies will double the amount allocated to this medium of communication in the next five years. Online marketing budgets will increase primarily to better target population increasing number entering the Internet and use this to substantiate a more and more decisions.

According to Forrester forecasts, budgets allocated to online marketing by companies in Western Europe will grow from 7.5 billion since 2006 to over 16 billion euros in 2012. The increase will not only absolute but in relative terms: if last year in these countries is spent online only $9 \%$ of the total marketing firms, in 2012 the share will reach $18 \%$.

This trend starts to be felt in Romania, where the pace of growth is higher than in western countries, due to start at a low level of development of the market. The amount budget for online marketing in our country is estimated at only nine million euros. In Romania, access to the Internet population of young urban, age up to 40 years, reached a high level. The audience will grow from year to year, marketing costs are low and benefits are clear. In addition, increases the number of hours spent on the Internet and purchasing decisions are based increasingly on research than before, sometimes quite detailed, the Internet market.

While in Romania, most of the online marketing budget is spent on ads in the form of banners, the trend at the European level is different. Western European companies will spend this year 4.5 billion euros, or $50 \%$ of the budget for marketing actions search engines. The budget allocated to advertising through banners in Western Europe is three billion, and the marketing via email, of 1.3 billion.

\section{Conclusions:}

Currently, investment promotion tools that give Internet is clearly favorable investment promotion through the classics: written press, television, outdoor.

Awareness of the importance of communication, reduced costs involved in communicating over the Internet led to an explosion of messages sent through the Internet, without regard to quality. Like any other medium of communication and the Internet proved its efficiency through imagebuilding over time. The amount is equivalent to quality, it should be the first concern of those who use this medium of communication.

The Internet is certainly the newest market for various businesses. Provide sufficient space for any entrepreneur, may start a business and investment low, sometimes even without financial resources and eliminates the physical distance, providing access to a much larger number of potential customers.

The Internet is an extremely dynamic. The competition is becoming greater, and customers are just a few click away from your competitors, making the level of loyalty in the online environment should be reduced.

\section{References:}

[1] Balaure V. (coord), Adăscăliței V., Bălan C., Boboc Şt., Cătoiu I., Olteanu V., Pop Al. N., Teodorescu N. (2002), Marketing, Editura Uranus, Bucureşti

[2] Epuran Gh. (1999), Cybermarketing. Publicitate şi eficiență pe Internet, Editura Plumb, Bacău

[3] Epuran Gh. (2007), Marketing pe Internet (suport de curs), Editura Univ. Bacău, Bacău 
[4] Epuran Gh. (1998), Tehnici promoționale. Fundamente teoretice, strategii, modele de decizie, Editura Univ. Bacău, Bacău

[5] Kotler Ph. (1999), Principiile marketingului, Editura Teora, București

[6] Kotler Ph. (1997), Managementul marketingului, Editura Teora, Bucureşti

[7] www.capital.ro

[8] www.ebusiness.org

[9] www.economist.com

[10] www.epayment.ro

[11] www.mediainfo.com

[12] www.netsun.ro

[13] www.news.com

[14] www.online.ro

[15] www.trafic.ro

[16] www.wall-street.ro 